\title{
Phenotypic identity of gastric mucous neck cells and mucous cells of cardiac, pyloric, and Brunner's glands
}

\author{
N R Hughes, P S Bhathal, D M A Francis
}

\begin{abstract}
Aim-To investigate the tissue specificity of a novel monoclonal antibody raised to a tissue fraction of normal human liver and which identified certain cells of gastric and duodenal mucosa.
\end{abstract}

Methods-A total of 155 samples of various tissues obtained from 100 surgical specimens were fixed in cold ethanolparaformaldehyde, embedded in paraffin wax, and $3 \mu \mathrm{m}$ sections were studied by immunohistochemical and lectin staining procedures.

Results-Immunohistochemical staining showed a major tissue specific component which was strongly expressed by mucous neck cells of the body of the stomach, glands of the cardia and pyloric antrum, and by Brunner's glands. Staining for antigen in the periductal glands of normal major biliary and pancreatic ducts was variable and relatively weaker. It was not detected elsewhere in normal intestine or in the other normal tissues tested. Barrett's mucosa of gastric cardia type, and pyloric gland metaplasia in the gall bladder and small bowel affected with Crohn's disease stained for the antigen. The tissue distribution of the antigen was identical with that of a glycoprotein, demonstrated by an induced affinity for concanavalin A following treatment of tissue sections with periodic acid. The antigen was not sensitive to sialidase.

Conclusions-The tissue component identified (designated here as antigen D10) seems to be characteristic of certain differentiated epithelial cells derived from that part of foregut giving rise to stomach, duodenum, and biliary and pancreatic ducts. The antibody will be of use in investigating pathological processes involving tissue differentiation at these sites, and in the oesophagus and intestines.

Department of
Anatomical Pathology,
The Royal Melbourne
Hospital, Parkville,
Victoria 3050,
Australia
N R Hughes
P S Bhathal
Department of
Surgery
D M A Francis
Correspondence to:
Professor P S Bhathal
Accepted for publication
18 August 1993

(F Clin Pathol 1994;47:53-57)

Brunner's glands form a continuous series of branched tubular glands in the mucosa and submucosa of the first part of the duodenum. More distally, they decrease in size and number until only a few small glands can usually be found in the third part of the duodenum. ${ }^{1}$ The morphological similarity of gastric mucous neck cells and cells of pyloric glands with those of Brunner's glands has been docu- mented before, ${ }^{2}$ and a similarity in staining of these three cell types has been shown in rat tissues by their induced affinity for concanavalin A (Con A) following treatment of sections with periodic acid and reduction with sodium borohydride. ${ }^{3}$ This Con A staining procedure has also been used to stain metaplastic glands, resembling pyloric glands, present in the intrahepatic bile ducts of subjects with hepatolithiasis ${ }^{4}$ and in ducts of pancreas containing ductal carcinoma. ${ }^{5}$

\section{Methods}

Tissues were collected from surgical specimens (as approved by the Ethics Committee of The Royal Melbourne Hospital) from 53 men and 47 women admitted to this hospital for surgery for various benign and malignant disorders. The 100 surgical specimens provided 155 samples of tissue from various organs. Three livers rejected for organ transplantation were also studied. Of the 100 surgical specimens, 92 were received fresh and tissues from these were fixed for 3 to 4 hours in ice-cold fixative containing $2 \%$ paraformaldehyde, $75 \%$ ethanol, and $0.4 \%$ cetylpyridinium chloride, dehydrated in isopropanol, cleared in chloroform, and vacuum embedded in paraffin wax for 1 hour. In the case of specimens of oesophagus, stomach, and intestine, following preliminary fixation for at least 1 hour, continuous strips of mucosa were dissected free from the muscularis propria, placed in fresh fixative for the additional necessary time, fashioned into "Swiss rolls" and then processed for sectioning as above. The remaining eight specimens were fixed in $4 \%$ buffered formaldehyde and machine processed as for routine pathological examination. For comparison of immunohistochemical staining, sections of tissue from 10 specimens which had tissue processed by both procedures were also studied.

\section{PRODUCTION OF MONOCLONAL ANTIBODY}

5HL-5D11-D10

Part of the left lobe of a human liver, resected for a haemangioma, was used as the source of antigen for immunisation. Macroscopically normal liver was diced in Dulbecco's modified Eagle's medium (DMEM), centrifuged at $200 \times g$ and $50 \mathrm{ml}$ of the packed tissue extracted by temperature-dependent phase separation with Triton X-114..$^{6}$ In brief, the tissue was suspended in ice-cold $0.5 \%$ Triton $\mathrm{X}-114$ and then phenylmethanesulphonyl fluoride and EDTA were added each to a 
final concentration of $2 \mathrm{mM}$ and the tissue homogenised in the cold using a Polytron homogeniser (Kinematica, Luzern, Switzerland). The homogenate was centrifuged in the cold at $2000 \times g$, the deposit again homogenised with ice cold $0.5 \%$ Triton $\mathrm{X}-114$ and centrifuged as before, and the two supernatant fluids combined. The supernatant fluid was warmed to $37^{\circ} \mathrm{C}$ in a water bath and centrifuged at $200 \times g$ at room temperature. The detergent phase, which contains detergent-soluble membrane proteins, separated as a lower oily layer and was discarded. The supernatant fluid was removed, cooled on ice, and acetone at $-15^{\circ} \mathrm{C}$ added to a final concentration of $60 \%$. The solution was held at $-15^{\circ} \mathrm{C}$ overnight, the precipitated proteins recovered by centrifuging at $4^{\circ} \mathrm{C}$ were redissolved in phosphate buffered saline and used for immunisation.

$\mathrm{BALB} / \mathrm{c}$ mice were given three intraperitoneal and two subcutaneous injections of the liver proteins over 13 weeks. Each injection contained $2.5-3.75 \mathrm{mg}$ of protein in 100-150 $\mu \mathrm{l}$. The first intraperitoneal injection was combined with an equal volume of Freund's complete adjuvant and the last with incomplete adjuvant four days before killing the mice. Isolated spleen cells were fused with the SP2/O-Ag14 mouse myeloma cell line, as described by others. ${ }^{7}$ Appropriate dilutions of the fused cells were cultured in 96-well plates in HAT medium for 14 days, and the supernatant fluid from wells containing a single hybridoma colony tested for antibody by immunofluorescence staining of sections of a mosaic of tissues. Tissues included were gall bladder, common bile duct, liver, pancreas, colon, duodenum and stomach.

One of the hybridomas tested stained the mucous neck cells of gastric mucosa, submucosal glands present in gall bladder, and Brunner's glands in duodenum. This hybridoma, coded 5HL-5D11-D10, was subcultured, cloned by limiting dilution, grown intraperitoneally in BALB/c mice. The one batch of ascites fluid obtained was used as antibody for immunohistochemical staining in the present study at a dilution of 1 in 500 . The monoclonal antibody present was shown to be an IgG of subclass $2 a$ and $\lambda$ light chain composition.

\section{IMMUNOHISTOCHEMICAL STAINING}

A four stage staining procedure was used. This involved incubating sections sequentially with TRIS buffer $(140 \mathrm{mM} \mathrm{NaCl}, 50 \mathrm{mM}$ TRIS, $2.7 \mathrm{mM} \mathrm{KCl}, 0.01 \%$ merthiolate, $\mathrm{pH}$ $7 \cdot 2$ ) containing $10 \%$ fetal calf serum, mouse monoclonal antibody, rabbit antibody to mouse immunoglobulins (Dako Z259), 1.5\% $\mathrm{H}_{2} \mathrm{O}_{2}$ in TRIS buffer, swine antibody to rabbit immunoglobulins (Dako Z196) and horseradish peroxidase-anti-peroxidase (Dako Z113). The substrate 3-3'-diaminobenzidine was used to demonstrate sites of bound enzyme. The immunological reagents were diluted in TRIS buffer containing $10 \%$ fetal calf serum, and sections were washed between changes for 5-10 minutes in TRIS buffer. In the case of sections oxidised with $2 \cdot 28 \%$ periodic acid before immunohistochemical staining (see below) treatment with $\mathrm{H}_{2} \mathrm{O}_{2}$ was omitted. ${ }^{8}$ Other sections were stained for 5 minutes in 1\% alcian blue in 3\% acetic acid ( $\mathrm{pH} \mathrm{2.5)} \mathrm{following} \mathrm{immunohisto-}$ chemical staining.

\section{SIALIDASE TREATMENT OF SECTIONS}

Paraffin wax sections were brought down to water and incubated in $0.2 \mathrm{M}$ acetate buffer, $\mathrm{pH} 5 \cdot 5$, containing $1 \% \mathrm{CaCl}_{2}$ and either 0.5 units $/ \mathrm{ml}$ of sialidase (neuraminidase) from Vibrio cholerae (Boehringer Mannheim Australia) or 1 unit of sialidase from Clostridium perfringens (Sigma, St Louis, Missouri, USA) for $22-24$ hours at $37^{\circ} \mathrm{C}$. Control sections were incubated in acetate buffer without enzyme for the same time. Sections were then washed in TRIS buffer, $\mathrm{pH} 7 \cdot 2$, and stained for antigen as described above.

STAINING SECTIONS WITH CONCANAVALIN A Dewaxed sections were taken down to water, placed in $1 \%$ or $2 \cdot 8 \%$ aqueous periodic acid for 10 minutes at room temperature, and then either in $0.2 \% \mathrm{NaBH}_{4}$ in $1 \% \mathrm{Na}_{2} \mathrm{PO}_{4}$ for 2 minutes or stained with Schiff's reagent for 10 minutes. Sections were then incubated in $10 \mu \mathrm{g} / \mathrm{ml}$ of biotinylated Con A (Vector Laboratories, Burlingame, California, USA) in TRIS buffer for 30-60 minutes, washed in TRIS buffer for 10 minutes, incubated with avidin-horseradish peroxidase (Silenus Laboratories, Melbourne, Victoria, Australia) diluted 1 in 200 with TRIS buffer fetal calf serum for 45 minutes, rinsed in TRIS buffer, and the colour developed using 3-3'diaminobenzidine as substrate.

The terminology used for the mucous cells and glands of oesophagus, stomach, and duodenum conforms with that used by De Nardi and Riddell, ${ }^{9}$ Owen, ${ }^{10}$ and Segal and Petras. ${ }^{1}$

Tissue samples staining immunohistochemically for antigen D10

\begin{tabular}{lcll}
\hline Tissue & Epithelium & $\begin{array}{l}\text { Submucosal } \\
\text { glands }\end{array}$ & $\begin{array}{l}\text { Periductal } \\
\text { glands }\end{array}$ \\
\hline Oral mucosa & $0 / 1^{\star}$ & $0 / 1$ & \\
Submandibular gland & $0 / 1$ & & \\
Parotid gland & $0 / 2$ & $0 / 3$ & \\
Pharynx & $0 / 4$ & $0 / 1$ & \\
Larynx & $0 / 1$ & $0 / 1$ & \\
Trachea & $0 / 1$ & $0 / 3$ & \\
Bronchus & $0 / 4$ & $0 / 2$ & \\
Oesophagus & $0 / 15$ & 0 & \\
Stomach & $24 / 24$ & & \\
Duodenum & $6 / 6$ & & \\
Ileum & $4 / 16$ & & $12 / 13$ \\
Pancreas & & & \\
Ducts & $5 / 15$ & & $6 / 6$ \\
Colon & $0 / 15$ & & $8 / 8$ \\
Liver & & & \\
Intrahepatic ducts & $5 / 7$ & & \\
Common bile duct & $3 / 8$ & & \\
Gall bladder & $8 / 13$ & $7 / 9$ & \\
Breast & $0 / 6$ & & \\
Endocervix & $0 / 2$ & & \\
Ovary & $0 / 1$ & & \\
Fallopian tube & $0 / 1$ & & \\
Adrenal & $0 / 2$ & & \\
Thyroid & $0 / 1$ & & \\
Spleen & $0 / 2$ & & \\
Kidney & $0 / 5$ & & \\
Ureter & $0 / 1$ & & \\
Skin & $0 / 5$ & & \\
T & &
\end{tabular}

${ }^{\star}$ Number of tissue samples staining for antigen/the number of samples tested. 

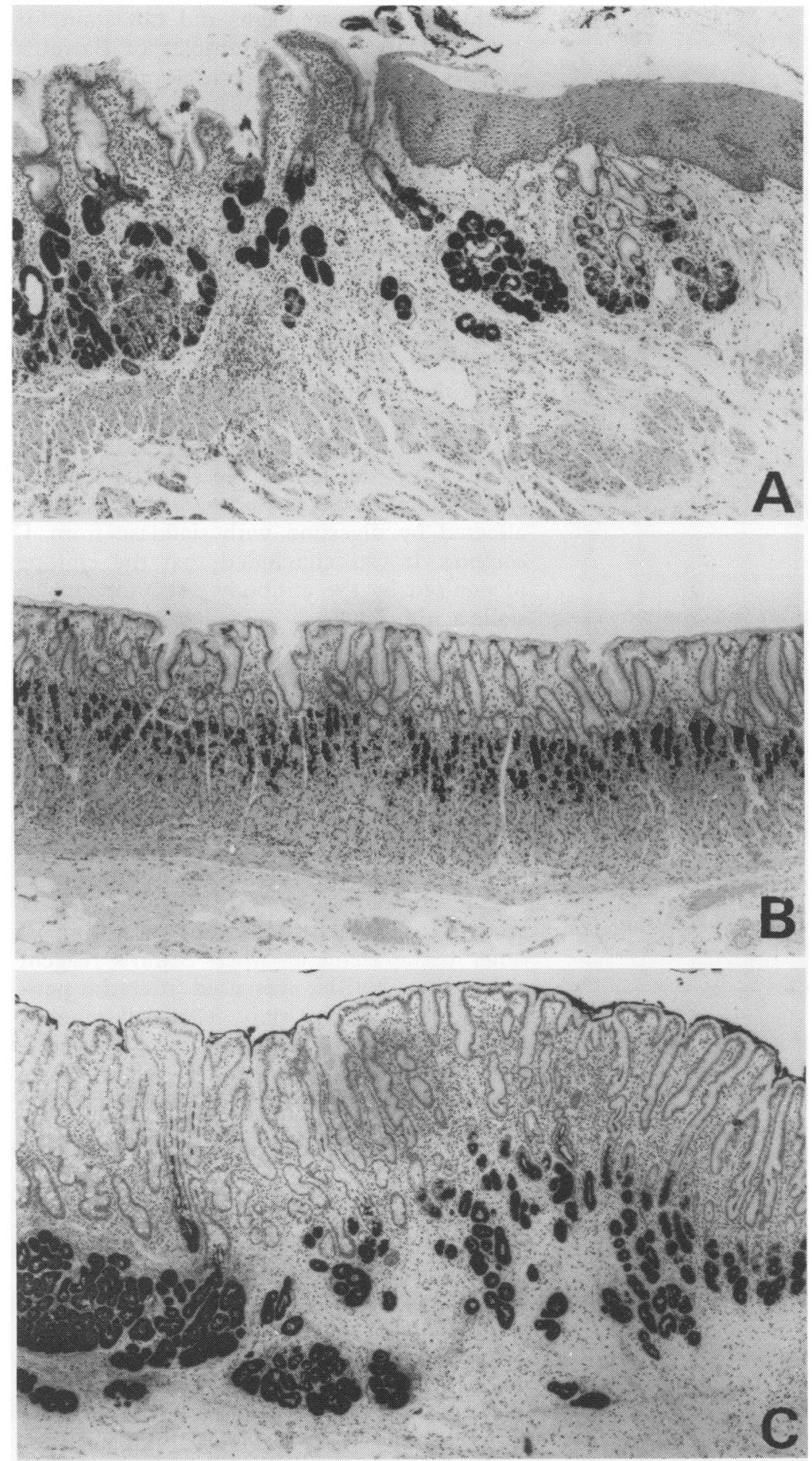

Figure 1 Sections of "Swiss rolls" of mucosa stained immunohistochemically for antigen $D 10$ and counterstained with haematoxylin. $(A)$ the cardio-oesophageal junction with the oesophageal mucosa (right) unstained and with an oesophageal cardiac gland and the glands of cardia staining strongly. (B) Body of stomach showing strong staining of mucous neck cells. (C) Gastroduodenal junction showing strong staining of pyloric glands (far right) and Brunner's glands. gland metaplasia in the ileum and gall bladder.

Oesophageal cardiac glands of the terminal oesophagus ${ }^{9}$ stained for antigen in the one specimen in which such glands were seen, but none of six submucosal glands found in the more proximal oesophagus of two resection specimens did so. The surface and foveolar epithelium were unstained in 19 of the 24 "Swiss rolls" of gastric mucosa studied, but there was a weak, finely granular, cytoplasmic staining of antigen in surface epithelium and foveolae in the other five. In each of the seven "Swiss rolls", which included gastric cardiac mucosa, all cells of the cardiac glands stained strongly (fig $1 \mathrm{~A}$ ).

In the body of the stomach staining for antigen D10 was generally restricted to the neck portion of the glands (fig 1B). The cells staining for antigen D10 were generally wedge-shaped and had basal nuclei. When sections were sequentially stained for both the antigen and with periodic acid Schiff (PAS), these cells showed a combined magenta and brown stain of the two reaction products. The antigen positive cells did not seem to stain as strongly with PAS as those of the gastric surface and foveolar epithelium. No staining with alcian blue was seen in the antigen positive cells of sections stained sequentially for antigen and with alcian blue, except for weak blue staining in a very occasional cell situated close to the isthmus. In their morphology, numbers, and position the antigen positive cells therefore corresponded to PAS positive, alcian blue negative, mucous neck cells. The D10 antigen was also found within the intracellular canaliculi of parietal cells (fig $2 \mathrm{~A}$ ), and free in the gland lumen.

In six "Swiss rolls" of mucosa which included pyloric antrum, the pyloric glands stained strongly for the antigen (fig $1 \mathrm{C}$ ).

Passing into duodenum, there was a short transitional zone in which the strongly staining pyloric glands increased in size and complexity similar to that of Brunner's glands. In "Swiss rolls" of the more distal parts of the duodenum only an occasional, small, strongly staining Brunner's gland was seen. Crypts into which Brunner's glands opened also contained some strongly staining cells.

Normal gall bladder and biliary epithelium did not stain for the antigen, except for a very occasional cell or small group of cells seen in three of 11 samples of gall bladder, three of eight samples of common bile duct, and the intrahepatic ducts of five of seven livers. Cells of the peribiliary glands in normal liver showed variable, generally weaker staining than those in stomach and duodenum (fig 2B). Hypertrophic, peribiliary mucous glands found in one of the three donor livers showed cells varying from none to strong staining. There was strong staining of pyloric gland metaplasia in another three gall bladders with chronic cholecystitis.

The epithelium of histologically normal pancreatic ducts did not express antigen D10 except for a very occasional cell in three of the 15 specimens examined. Non-papillary only normal organs to express the antigen were the stomach, duodenum, gall bladder, liver and pancreas. The antigen was also found in the oesophagus in Barrett's mucosa of gastric cardia type and at sites of pyloric 

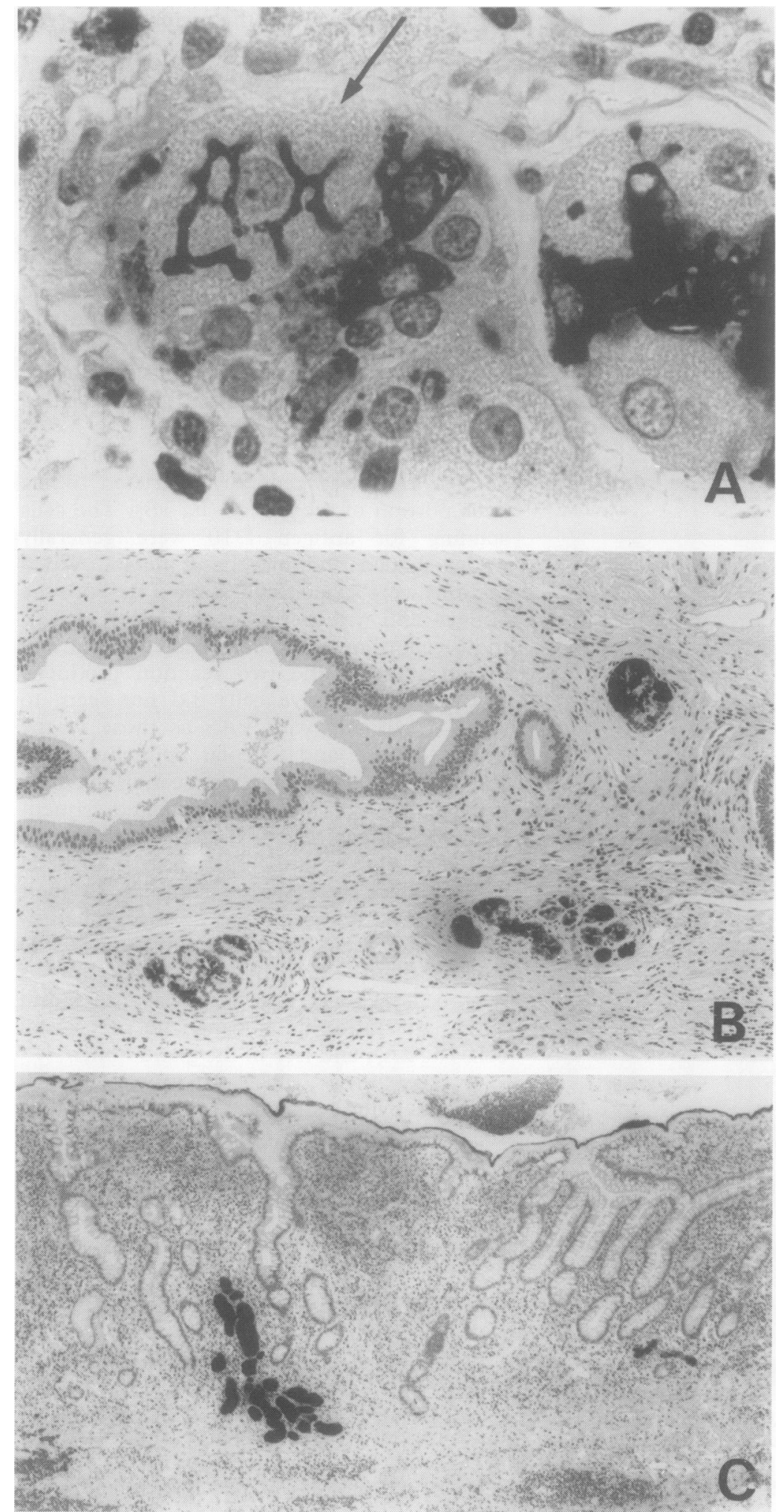

Figure 2 Sections of tissue stained immunohistochemically for antigen D10 and counterstained with haematoxylin. (A) Two glands of the body of stomach showing antigen in the cytoplasm of mucous neck cells and also within the intracellular canaliculus of a parietal cell (arrow). (B) Antigen present in peribiliary glands of a segmental bile duct. (C) Pyloric gland metaplasia staining strongly for antigen in a "Swiss roll" of terminal ileum with active Crohn's disease. Antigen is also present on the luminal aspect of the mucin covering the surface epithelium.

hyperplasia ${ }^{112}$ present in some larger dilated ducts stained strongly for the antigen, but mucous cell metaplasia (papillary hyperplasia), ${ }^{11}$ also present in the ducts of eight of the pancreatic specimens, showed little or no staining. Periductal glands showing mucous cell hypertrophy stained strongly. ${ }^{11}$

Five specimens of Barrett's oesophagus were studied. Although the normal squamous epithelium of oesophagus did not stain for antigen D10, all five examples of Barrett's mucosa showing gastric cardiac gland metaplasia stained strongly. Of four adenocarcinomas arising in Barrett's oesophagus, three did not stain, but the fourth showed many tumour cells staining for antigen D10. Three squamous cell carcinomas arising in the oesophagus did not stain for antigen.

Normal jejunum, ileum, and colon did not stain for the antigen. In four ileal specimens of Crohn's disease showing pyloric gland metaplasia, however, there was strong staining of the metaplastic glands for antigen D10 (fig 2C).

The reactivity of antibody 5HL-5D11-D10 was slightly reduced by digestion of sections with sialidase from $C$ perfringens but was unaffected by digestion with sialidase from $V$ cholerae. It was concluded that the epitope recognised by the antibody does not involve sialic acid residues.

Prior treatment of sections with periodic acid did not affect the immunohistochemical staining of antigen D10. This was the case irrespective of whether aldehyde groups produced by the periodic acid were inactivated with $\mathrm{NaBH}_{4}$ or Schiff's reagent.

When sections were treated with periodic acid, mucous neck cells and cardiac and pyloric glands in stomach and Brunner's glands showed binding of Con A. There seemed to be less background staining of other tissue elements when Schiff's reagent rather than $\mathrm{NaBH}_{4}$ was used after the periodic acid oxidation step. Although mucous neck cells showed only slight PAS positivity, cardiac, pyloric, and Brunner's glands were strongly PAS positive. Periductal gland cells in liver and pancreas showed weak specific staining with Con A and also contained PAS positive material.

Major and minor salivary glands-namely, the parotid and submandibular glands and oral mucosal glands, and submucosal glands of the larynx, trachea, and bronchi and of the oesophagus - did not bind Con A after periodic acid oxidation.

Treating sections with periodic acid, reducing with $\mathrm{NaBH}_{4}$, and then incubating with antibody 5HL-5D11-D10, did not prevent subsequent binding of Con $A$ to mucous neck cells, or cardiac, pyloric, and Brunner's glands. Conversely, treating sections with periodic acid and $\mathrm{NaBH}_{4}$ and then incubating with Con A, did not prevent subsequent immunohistochemical staining of the antigen.

\section{Discussion}

The cell phenotype identified by positive staining for the D10 antigen was characteristic of mucous neck cells of the body of the stomach and the cells comprising the cardiac and pyloric glands. By staining "Swiss rolls" of mucosa for antigen D10, the continuity of the cell phenotype through mucous neck cells of the gastric fundus, cardiac glands proximally, and the pyloric glands and Brunner's glands distally was clearly shown. At the pyloro-duodenal junction an increase in size 
and complexity of branching of glands accompanied the transformation of pyloric glands to submucosal Brunner's glands. The periductal glands of the major biliary and pancreatic ducts are analogous to the glands of stomach and duodenum, and the fact that they express the D10 antigen is in keeping with the derivation of liver and pancreas from the first part of duodenum. This restriction of antigen expression to a limited region of the gastrointestinal tract indicates a specific encoding of stem cells forming the epithelium of that part of foregut giving rise to the stomach and duodenum. The presence of antigen D10 in Barrett's oesophagus and in the metaplastic glands seen in Crohn's ileitis, however, suggests that the gene repression imposed on most of the normal small intestine and all of large bowel is subordinate to that governing general gastrointestinal cell differentiation. Pyloric gland metaplasia in small bowel affected by Crohn's disease and other inflammatory bowel disease has been documented by others, ${ }^{13}$ and antigen D10 should prove a suitable marker to identify readily and study such metaplasia.

The cell type expressing antigen D10 in the glands of the stomach and duodenum is a mucus secreting cell, and in normal liver and pancreas that of a vacuolated, cuboidal cell lining the simple, tubular periductal glands. Judging by the strength of the immunohistochemical staining of the cytoplasm, it is a major component of the cells expressing it in the stomach and duodenum. Although secreted into the lumen of glands, antigen D10 was not generally admixed with the layer of mucin covering the surface epithelium of stomach and duodenum, but remained external to it. This suggests a different role to that of the neutral mucins secreted by the surface and foveolar epithelium of gastric mucosa.

The similar cell and tissue distribution of antigen D10 and the glycoprotein demonstrated by the periodate-Con A staining procedure suggested that the two could be identical. As oxidation with periodic acid did not affect the immunohistochemical staining of D10, the epitope recognised by antibody 5HL-5D11-D10 cannot involve the sugar moieties which need to be oxidised by periodic acid in order to allow the binding of Con A. Because Con A and the antibody did not interfere with one another in staining tissue sections, they must either bind to different sites on the same molecule or to different macromolecules. It will therefore be necessary to purify antigen D10 in order to determine if the two staining procedures recognise the same substance.

Although antigen D10 could be an epitope common to functionally diverse molecules, the cell and tissue specificity of the D10 antigen suggests some similarity in function of mucous neck cells and cardiac, pyloric, and Brunner's glands. Brunner's glands secrete neutral glycoprotein and lysozyme in an alkaline secretion, and it has been proposed that these secretions protect duodenal mucosa by neutralising the acid entering from the stomach. ${ }^{14}$ Brunner's glands also produce and secrete epidermal growth factor (urogastrone) which may play a part in healing intestinal erosions. ${ }^{15}$ Pyloric gland metaplasia in intestines found in association with Crohn's disease and gastric cardiac gland metaplasia in Barrett's mucosa ${ }^{16}$ may also have such a role. Whatever the function of antigen D10 in the gut lumen, it may also exert some effect within the gastric acid secreting tubules in view of the close spatial relation of mucous neck cells and parietal cells. It seems to be released into the lumen of gastric glands mainly in the form of granules, and this may explain why it does not readily mix with the mucins secreted by cells of foveolae and surface epithelium. In view of the apparently large amounts of D10 produced and secreted throughout stomach and duodenum, its role is likely to be of some importance.

Compared with cells of stomach and Brunner's glands, little antigen D10 seems to be produced in the periductal glands of normal liver and pancreas. Preliminary studies indicate, however, that increased amounts are present in the hyperplastic epithelium of dilated ducts, hypertrophic periductal glands, and in glands showing mucous cell metaplasia. This would be in keeping with the observations of others using the periodic acid Con A staining procedure, ${ }^{45}$ and suggests that antigen D10 may also be of use in studying disease processes in biliary and pancreatic duct disorders.

This work was supported by a grant from the National Health and Medical Research Council of Australia.

1 Segal GH, Petras RE. Small intestine. In: Sternberg SS, eds. Histology for pathologists. New York: Raven Press, 1992:547-71.

2 Bloom W, Fawcett DW. A textbook of histology. Philadelphia: WB Saunders Company, 1975:652.

3 Katsuyama T, Spicer SS. Histochemical differentiation of complex carbohydrates with variants of the concomplex carbohydrates with variants of 7 Histochem Cytochem 1978;26:233-50.

4 Kurumaya H, Terada T, Nakanuma Y. "Metaplastic lesions" in intrahepatic ducts in hepatolithiasis: A histochemical and immunohistochemical study. $f$ Gastroenterol Hepatol 1990;5:530-6.

5 Matsuzawa, K, Akamatsu T, Katsuyama T. Mucin histochemistry of pancreatic duct cell carcinoma, with special reference to organoid differentiation simulating gastric pyloric mucosa. Hum Pathol 1992;23:925-33.

6 Smythe JA, Murray PJ, Anders RF. Improved temperature-dependent phase separation using Triton X-114: isolation of integral membrane proteins of pathogenic parasites. Technique 1990;2:133-7.

7 Kohler G, Milstein C. Continuous cultures of fused cells secreting antibody of predefined specificity. Nature 1975;256:495-7.

8 Heyderman E, Neville AM. A shorter immunoperoxidase technique for the demonstration of carcinoembryonic antigen and other cell products. $\mathcal{F}$ Clin Pathol 1977; 30:138-40.

9 De Nardi FG, Riddell RH. Esophagus. In Sternberg SS, eds. Histology for pathologists. New York: Raven Press, 1992:515-31.

10 Owen DA. Stomach. In Sternberg SS, ed. Histology for pathologists. New York: Raven Press, 1992:533-45.

11 Kloppel G. Pancreatic, non-endocrine tumours. In: Kloppel G, Heitz PU, eds. Pancreatic pathology. Edinburgh: Churchill Livingstone, 1984:79-113.

12 Cubilla AL, Fitzgerald PJ. Morphological lesions associated with human primary invasive nonendocrine ciated with human primary invasive no

13 Lee FD. Pyloric metaplasia in the small intestine. 7 Pathol Bacteriol 1964;87:267-77.

14 Fenoglio-Preiser CM, Lantz PE, Listrom MB, Davis M, Rilke FO. The normal anatomy of the small intestine. In: Gastrointestinal pathology. An atlas and text, New York: Raven Press, 1989:242-3.

15 Wright NA, Pike C, Elia G. Induction of a novel epidermal growth factor secreting cell lineage by mucosal ulceration in human gastrointestinal stem cells. Nature 1990;343:82-5.

16 Janowski J, Coghill G, Tregaskis B, Hopwood D, Wormsley KG. Epidermal growth factor in the oesophagus. Gut 1992;33:1448-53. 